\title{
The Citizen Voice Project: An Intervention in Water Services in Rural South Africa
}

\author{
David Hemson and Imraan Buccus
}

Abstract Despite a legal framework for participation in South Africa, poor citizens have not to date been able to access the public services they need, leading some to talk of a 'second democracy', the political system as experienced by the poor. This action-research study involved local government, non-governmental organisations (NGOs), community leaders and community mobilisation to develop Water Services Scorecards, in rural Mbizana in the Eastern Cape. Water services had been grossly inadequate and were worsening. Communities were facilitated to analyse their own water-related problems; to establish standards and to measure services against indicators adapted from national policy frameworks. The case study documents the process, and reflects on its outcomes. It notes disappointment that service improvements had not been immediate. A crucial constraint, it concludes, was weak inter-level local government coordination; these are higher-order problems that local civil society action of the Citizen Voice Project type is not well positioned to tackle.

\section{Introduction}

Participation in South Africa is reaching a crossroads. Many important innovations that set the framework for action have not been able to bridge the gap that apartheid left between government and those in poverty. In this study, which included local government, nongovernmental organisations (NGOs) and tribal elders, community mobilisation culminated in 'Scorecards', which were introduced to facilitate community assessment of services and point to key areas of action. The results were both positive and negative, showing the very real difficulty that the challenge of building effective and accountable governments presents.

\subsection{Participation in South Africa: could there also be a 'second democracy'?}

South Africa has a fairly well-developed framework for participation (KwaZulu-Natal, DLGTA, undated), which sets out the rights to participation, particularly in local governance, including Ward Committees and local planning. The key instrument of democratic governance, Batho Pele, is built around the notion of an active citizenry and a responsive government. Taken together, these are important aspects of the government's strategy for reducing poverty by including poor citizens in participatory processes leading to empowerment and poverty alleviation. However, this promising framework has been undermined by unevenness in actual participation and the fact that for many, the results in improved service delivery are disproportional to the effort required. In South Africa, there is much talk of a 'second economy', that in which the majority population of poor people are engaged, as distinct from the 'first economy' constituted by South Africa's minority wealthy population. Some now talk of a 'second democracy', using the analogy to indicate the differential and uneven access of poor citizens to political and state institutions, compared to their wealthy compatriots.

As a result, protests, marches and demonstrations have swept through entire provinces, notably in the Free State in 2004, and regularly recur in poor communities in metropolitan areas. These protests show that many among the poor regard the processes of participation as irrelevant and instead adopt forms of direct action. Although the response of

IDS Bulletin Volume 40 Number 6 November 2009 (c) 2009 The Authors. Journal compilation (c) Institute of Development Studies Published by Blackwell Publishing Ltd, 9600 Garsington Road, Oxford OX4 2DQ, UK and 350 Main Street, Malden, MA 02148, USA 
government has often been extremely hostile to such movements, there is also acknowledgement that there are substantive issues, such as indifference by representatives to poor people's needs, corruption in local government tendering and poor financial management. A recent review of the past 15 years concluded that despite progress in service delivery - 89 per cent of the population now have access to piped water, for example - the poor remain dissatisfied and inequality is growing; economic growth has not been translated into reduced poverty (PCAS 2008: 30). The strategy of inclusion through the official procedures of public participation has not resulted in the anticipated fairer distribution of services.

Dissatisfaction is highest and service delivery levels lowest in rural areas. Demand for housing or improved housing is a common theme in the protests, and problems of access to water and sanitation persist, despite so-called progress. In urban contexts, concerns include restrictions on supply among the poor, while many rural areas experience irregular water supplies, slow delivery and periodic health crises, such as the cholera epidemic of 2000-01.

The project which served as the focus for the case study grew out of this concern with service provision and effective citizen participation. The participation of local people in reviewing delivery and voicing their grievances was seen as a spur to greater responsiveness from those municipalities responsible for water services. It took place at a time when water issues were in the political arena, with the Department of Water Affairs and Forestry (DWAF) in the process of developing a regulatory system for water service delivery. Despite ongoing involvement from civil society groups, there was concern that policy development had not reflected the issues raised in consultations. There has, however, been recognition of a key concept: that regulation involves people as citizens rather than customers - an important distinction which implies that regulation will involve people in participation and redress. While rural community groups were, in general, excluded from this process, the water regulation system set out a series of objectives for municipal government to reach and indicators to report on, providing a framework on which local communities could advocate action.

\section{The Citizen Voice Project}

The project was implemented in Mbizana, in the Eastern Cape, which includes two former 'homelands' and has a rich history of resistance to apartheid. The Eastern Cape is characterised by extreme inequalities of development and dependence on 'floundering' subsistence agriculture (Eastern Cape, PGDP 2004). The OR Tambo District Municipality, which includes Mbizana Local Municipality, contains some of the poorest rural communities, with high unemployment and growing crime rates. Some 88 per cent of households live below the minimum poverty level; 78 per cent have no access to piped water; and 93 per cent have no formal sanitation services. In fact, in Mbizana, access to piped water actually declined from 17 per cent to 5 per cent between 2001-07, while standpipe access similarly fell from 15 per cent to 5 per cent (STATSSA 2007: 44). This has resulted in widespread cholera outbreaks. As is the case for most municipalities, the district is both the Water Service Provider and the Water Service Authority for the Mbizana Local Municipality, although private contractors have been hired to assess the systems and for construction.

Responsibility for the project rested on a research group from the Human Sciences Research Council and a local civil society organisation, Bizana Community Legal Resources Centre (BCLRC). Initial contacts between the BCLRC and municipal officials were hopeful: the then Municipal Manager was interested in the prospects for training and development, and the Speaker enthusiastic about the idea of community appraisal. The cascade strategy of training facilitators and the communities was set out and discussed and important revisions introduced at the wishes of the municipality, to which the project team were also committed. These included an increase in the number of trainees and their accreditation in terms of the SAQA (South African Qualifications Authority) important for future recognition of their skills.

The project team's initial proposal was for an open-ended cascade system, to make use of rural social and institutional networks. The Council Speaker, however, requested a more formal allocation of Wards to trainers, to facilitate cooperation with Ward Councillors and allow upward movement of information to the Council (to whom they were required to report). It was 
Table 1 The project process

\section{Month (2008) Activity}

April Presentation to and discussion with the Mbizana Local Municipality

May $\quad$ Presentation to and discussion with OR Tambo District Municipal Officials and DUAF officials

June $\quad$ Training of the trainers course; assessed for knowledge and ability in learning and training

July/August Training and deployment of facilitators in Mbizana Wards 2, 19 and 20

November Two Ward Forums, Mbizana Local Municipality

felt that such support would give a coherent frame to the deployment of trainers, allow engagement with official structures at an early level, and ensure municipal responsiveness to the points arising. The reports from the Wards would constitute an important component in the relationship between local and district municipality. The offices of the OR Tambo District Municipality are in Mthatha (some four hours away) and the project would give weight to local priorities and hopefully lead to the negotiation of better links between local and district municipality on water services.

Another important local question was that of relationships, with the nine traditional authorities in the municipality. Through the BCLRC, links were established with traditional leaders and an initial presentation made. A key question raised was whether the project would work under the aegis of the traditional authorities. This was a matter of some complexity, as the number of Wards and their boundaries are subject to change and tend to cut across those of traditional authorities. As a result, and in preparing the initiative, the trainees were selected from nominations received from both the traditional authorities and civil society (Table 1).

\subsection{The project in action}

\section{Capacity development and community mobilisation}

The project had considerable potential to build rural community capacity to undertake autonomous assessment of water services. The local authority supported the project, with the Speaker providing strong endorsement and Ward Councillors' tacit support. One attractive feature of the project from the perspective of the municipality was its long period of training, capacity building and community mobilisation, with which came large folders (the 'Big Book') kept in villages as repositories for original copies of community documents, which were photographed and stored electronically.

The project produced a series of comprehensive materials for communities to use as prompts to speakers or for community reports during consultation on community needs. In the three Wards, four team leaders and 21 facilitators were trained and working, along with other active members of the different communities. A distinction was made between a trainer, facilitator, and active member of the public, in terms of materials and methods. A trainer was regarded as a Development Practitioner who had been given specific training in teaching and in particular, an understanding of cascade methodology. A facilitator was a Practitioner with experience, training in community appraisal, but without the wider range of skills or specific training in teaching. Finally, the Active Gitizens were provided with posters and pamphlets presenting basic information on rights and processes in the provision of water services.

Starting with their home village, the trainers trained facilitators and took them to the other villages in the Ward to make a full appraisal of community history, needs and aspirations. This involved exercises in learning by doing - starting with rights education in the community and proceeding to using tools adapted from participatory research for the purpose. A community and water mapping exercise provided a rapid overview of water resources and projects. This was followed by exercises dealing with the health of under-fives (the 'diarrhoea diary') and the distances children carry water. Trainers and village facilitators worked with youth, women, church and other groups as a Task Team to undertake these basic village-level analyses. The community mobilisation concluded in a 
1 Communication of municipality with community

2 Water: participation in planning for water services

3 Water: provision of Free Basic Water at 200 litres/household/day

4 Water: access for all or date of access for all is known

5 Water: facilities are working with proper flow

6 Water: quality of water is known

7 Sanitation facilities: access or date of access for all is known

8 Sanitation: public facilities (clinics, schools, courts) have toilets

9 Hygiene facilities: children's needs for hand washing met at school

10 Hygiene: health promotion undertaken and health of under-fives improving

community meeting in which a Scorecard with an assessment of water services was drawn up, including a village action plan on how to engage political representatives and municipal officials in the improvement of services. This was designed around the Ward Forum, at which the councillor and officials were to be present. The community presentation here was designed to provide the councillors with the data to put the case at the local municipality and from there, to the district municipality.

\section{The Water Services Scorecard}

A key challenge to the project was the understandable expectation within communities that mobilisation should address all aspects of service delivery: priorities included electricity, roads, agricultural extension and community facilities, as well as water and sanitation. A limitation was that the project was funded on the basis that there would be a dedicated focus on the sustainability of water and sanitation services, ${ }^{1}$ rather than a wider examination of all potential services. Most community members accepted this limitation, as they also suffered from a critical lack of water and sanitation.

The need to achieve a readily understood conclusion to the community appraisal was fulfilled through a simple Scorecard, which drew together the results of the various exercises under ten criteria designed to measure the implementation and effectiveness of water services, including an indicator of public participation and one of health promotion. These were focused on key indicators drawn from national policy documents, such as the Strategic
Framework for Water Services and National Water Sector Regulations.

The Scorecard summarised the tools employed in community appraisal, focusing attention on the essential indicators for regulation and other key public commitments with respect to water services. It had the advantages of being numerical, standardised around key national indicators, sensitive to variability among different communities and expressing citizen's voice on each of the key issues.

\subsection{Results of the Scorecard exercise}

The ratings produced by the Scorecards indicated that water service delivery levels were extremely low (Figure 1). On a scale of 1-10, the highest rating was for communication - a mere score of 3 - and indicators of actual delivery were zero (0). These ratings reflected the real situation in most villages, where there was either no infrastructure or in which taps had run dry. There was a similar very low level of sanitation service delivery. Compared with urban slum areas, the indicators show lower levels of communication but higher levels of access from standpipes at the roads, and better conditions in schools.

\section{The impact of the project}

Although the project succeeded in generating and capturing evidence of the difficulties with water services and related issues such as the health of under-fives, it did not bring about an immediate improvement in people's lives. Communication was achieved but not redress. The project raised a wide range of possibilities which led to 


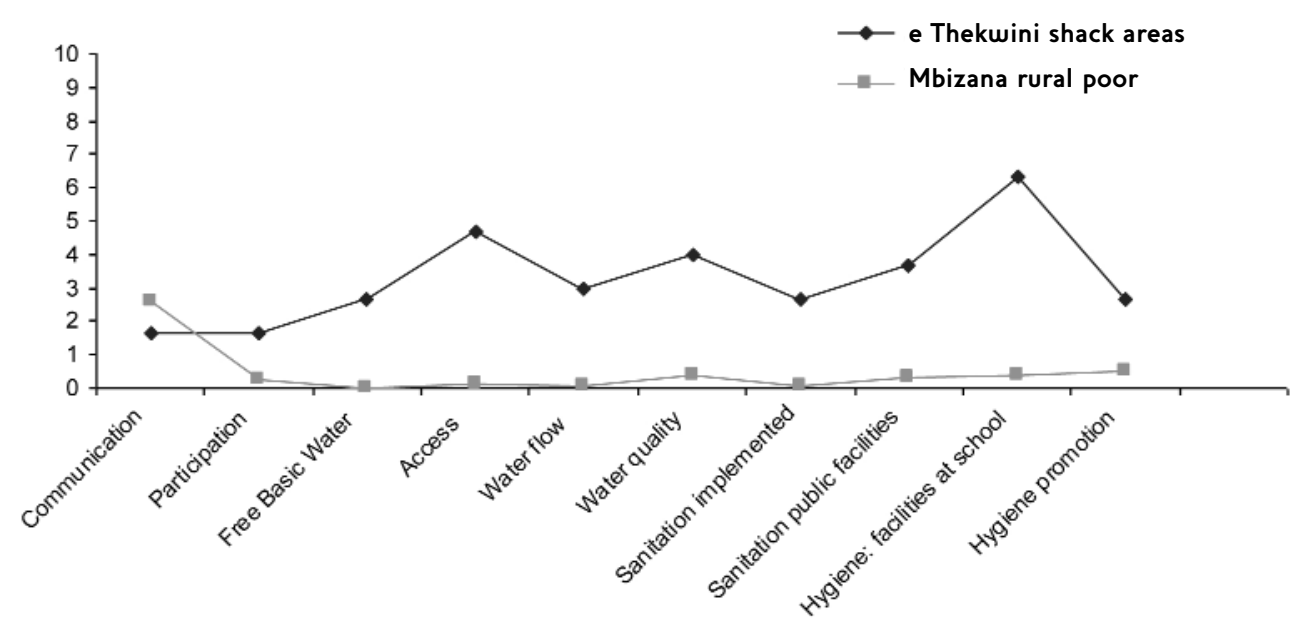

Line items, ranked out of 10

communities feeling empowered, yet there remained difficulties in crossing the divide between community and political structures.

\subsection{Municipal responsiveness: the challenges of institutional architecture}

The difficulty was largely, but not exclusively, with communication and responsiveness between different political structures. While the project achieved citizen voice, it could not bridge the divide between citizens and their political representatives, and particularly between local and district municipalities. The divide between the local and district levels was increasingly acknowledged as the crucial determinant of impact, given that the statutory competence for the sector falls to the district municipality as both Water Service Authority and Water Service Provider. Although discussions were held with the district municipality before the project was initiated, there was greater interaction with the local municipality. The traditional authorities which are important in the local context were consulted and involved at one level or another in the implementation of the project. In most of the village meetings, the headmen were invited and involved.

Throughout the study, training communication had been good with local municipal officials. There were two points in the process during which the assessment by the trainers and Scorecard results were shared with municipal politicians and officials. The first was the Ward
Forums where the community shared the results of the community appraisal with the Ward Councillor. The second occurred when the project research team met with both district and local municipal officials, in an attempt to improve communication between the two levels on the results of the project.

Unfortunately, some turnover in the staff of the district municipality meant officials who had previously been engaged in the process were re-deployed elsewhere. At the first report-back meeting, municipal officials were interested in the information about communities, and particularly concerned about reports of water-related diseases, but asked for a further meeting to reflect. At this second meeting, the presentation attempted to encourage a favourable municipal response. The focus was on the prospects for immediate action to improve operations and maintenance, presented by a United Nations Development Programme (UNDP) engineer attached to the Mbizana Local Municipality (Hoogerwerf 2007). This meeting, however, ended inconclusively and the proposal to have a local water summit between the district and local municipality with civil society groups present to hear plans and prepare contributions was not taken up.

Although both tiers of municipal government are controlled politically by the African National Congress, there were a number of obstacles that prevented community action leading on to communication and an appropriate response: 
- It was not clear how the local municipality used the reports in their advocacy for better conditions.

- The reactions of district municipal officials to the project results were mixed, combining an appreciation of the value of the community analysis and Scorecard reports with uncertainty of how to respond. A listing of priorities for action to improve services appeared to antagonise rather than encourage.

- The longer-term response from the local municipality has been to allocate full responsibility for remedial action to the district municipality.

This lack of municipal consultation and responsiveness is not confined to the water services sector, nor to Mbizana District. Instead, it is common to rural municipalities across South Africa. The most recent South Africa Social Attitudes Survey (SASAS) found that 67 per cent of South Africans felt that municipalities do not consult communities, and 52 per cent that municipalities do a poor job of following through and addressing problems. ${ }^{2}$ The impression that emerges from these statistics and from engagement with municipalities is of an intense preoccupation with immediate and internal priorities, largely independent of broad objectives, such as water and sanitation issues in rural areas. A scan of Integrated Development Plans (IDP) indicates a wealth of data and maps but no operational schedule for projects. ${ }^{3}$ In an interview with a key official in a rural municipality it was noted that the IDP ultimately entails a one-page schedule of projects to be actioned, often concluded well after the beginning of the financial year.

\subsection{Public assessment of the project}

The research undertook to assess the impact of the project through assessments by the public of its impact, through focus group discussions with citizens and trainers, and individual interviews with municipal officials, politicians and facilitators. The topics discussed related to the overall assessment of the project and its methods, and its contribution towards changing power relations between actors, and impact on water and sanitation services.

In terms of the Citizen Voice Project itself, there was a feeling that the objective had been achieved. Municipal officials and trainers were unanimous in stating that the communities had achieved voice through the project, understanding their rights, spelling out their needs, understanding procedures, producing reports and the Scorecard, and interacting with official structures:

What was done was a major step to bringing people into the fold of their own development and also assisting people to have their own voice and to understand what was happening in their communities. (Municipal official)

The community has been able to voice out its opinions not only on water and sanitation, but also on other issues. As Batho Pele says, people's voice first. (Trainer)

Other strengths of the project included its approach to mobilising the community through building new capacity and leadership among local people, including many who were not already deeply embedded in leadership roles in their communities:

The project brought in people who were not well established but social activists in their own areas who were very useful in interacting with councillors responsible for development. (Municipal official)

In other projects strangers simply come and go, this one was made known to the local people. Moreover, the local people were also involved in its implementation. When they have problems they know who to contact. (Trainer)

The project was also seen as empowering, in that those who were often the least included were given priority, particularly women.

Some also felt that the project was correctly focused and led to important gains within the communities, including on priority-setting:

The project is good water and sanitation as priority number one. For example, there is no point in having electricity without clean water - one ends up getting sick with diarrhoea. It is worse during the rainy season because the river carries all the impurities. (Trainer) 
As a result of this project, people realise that they have a right to decide on prioritising their needs, for example water first. (Trainer)

It is good because the community know to voice out their needs. (Trainer)

In addition, the project developed and deepened local knowledge:

This project has made a difference, in the sense that we now know our villages better. Many people did not know about the structure of their villages. As we went around drawing maps, people got to know what was there or not in their village. They were happy. People are now aware of different needs in various communities. (Trainer)

From the municipal officials, councillors and trainers, there was also general endorsement of the project for its initial approach, its inclusivity, its focus on the critical water sector, the training, the skills transferred to the community, and the involvement of youth and women.

For many citizens, however, the project gains in terms of voice, knowledge, capacity and leadership, and inclusiveness were of limited value because to date, improvements to water and sanitation services have yet to be implemented:

Our local municipality did not come back to us. We are in the dark now as we know nothing. If there were reports to the local municipality, they ought to have reported back to the community and say 'people, this is the project'. (Citizen)

Many felt that while the project strengthened the trainers, transferred skills to facilitators and directly to the communities, it failed to achieve the desired changes in service delivery. Where local water and sanitation projects are still operational, communities continue to be poorly served. In most of these communities there is still no piped water available or improved sanitation; the situation in the municipality continues to decline.

There is no report back from the councillor to the community. (Facilitator)
There is no communication, the gap between the people and the municipality is still there. (Trainer)

People are not satisfied at all. In fact there is no service delivery. When we moved from one village to the next, people thought we were going to build toilets. We then explained to them that we were doing research to enable them to voice out their needs. For example, we were checking if there were toilets or not; if not, why not? - was there clean or dirty water; if dirty, why? - what could be done? For such questions, and opinions to come from the community was a good step forward. This project helped people to speak out. This was a wake-up call for the municipality to do their work. So far there has not been any result. (Trainer)

The response of the trainers to these criticisms is that the project should continue and be expanded to constantly pursue communication from below until the district municipality has effectively responded and the community achieved proper delivery:

The project must train the stakeholders, for example local members, Ward Councillors, chiefs and headmen. There must be a communication network. (Trainer)

The project must continue sending reports to various stakeholders. Maybe in the end something will happen. (Trainer)

My feeling is that the project must continue, I think the problem around poor service delivery is money/funds: what have they done with it? Budget allocations must be used to improve the living conditions in the communities. (Trainer)

One of the most difficult institutional obstacles to an effective response to the Gitizen Voice project has been the relationship between local and district municipalities. It is even possible that the project may have exacerbated tensions within those relationships, as it frequently provided graphic representation of local needs, and highlighted failures of implementation. 
The district municipality was not so happy but I don't know who was doing the implementation. (Councillor)

They [district municipal officials] felt they were being beaten, but the function was theirs and they should have got better results.

(Municipal office)

There were not enough discussions with the district municipality, which is the custodian of water provision, and more discussions to get them on board would have made things better. (Municipal official)

The major failure is the intersection between local and district municipality; we were working as if we were living in different countries. (Politician)

Although the project team had anticipated some difficulties between the different tiers of local government, it had failed to take into account the severity of the difficulties of the relationships between the two levels of government. The continuous communication and conflict resolution needed to make a system of divided responsibility work had proved to be beyond the scope of the project. Part of the problems lie in a lack of structured coordination:

There is not a formal relationship of coordination amongst us; this has never been structured, but we are working to drive development together. (Municipal official)

The lack of a formal coordination system can permit Ward Councillors and local municipalities to devolve all responsibility for implementation and response upward, to the district municipality. Local leaders tend to be less interested in exploring how this relationship could be improved than on insisting that service delivery should happen. Local councillors also feel they lack capacity to act on this issue, and the Citizen Voice project was partly seen as a way of resolving this issue.

On the part of civil society, municipal officials and politicians, the methods and implementation of the project were generally supported, but there was a sense that more time was needed for the relationships and the situation to evolve to strengthen municipal responsiveness. There was also recognition of the impacts of the changing political environment, including confusion resulting from splits within the political leadership of the local municipality, against the larger background of divisions within the central African National Congress in 2008. In this political climate the notion of incremental progress, implicit in the original project design, was overtaken by complex political shifts internal to the African National Congress which recast the entire leadership among officials and key politicians.

\subsection{What difference did the Citizen Voice Project make, and how?}

The Citizen Voice Project focused on the possibilities of local community mobilisation, developing the capacities of a new set of local actors independent of local political structures and trained to a high professional standard to conduct wide-ranging community-level appraisals. To some extent, this shifted power relations between people and representatives; actively involving women in the community mobilisation generally, and as village facilitators. Civil society groups were affirmed and strengthened through this process. Within these communities, civil society had been weakly represented, chiefly composed of small Christian faith-based groups with a history of education and welfare provision. The Bizana Community Legal Resource Centre (BCLRG) was key to the intervention: it supported the concept, initiated discussions with traditional leaders, opened the door to local municipal officials and helped select candidates for training, despite operating with precarious funding at the time. This ultimately raised the status of the BCLRG within the community, and established its links to councillors, trainers, and communities.

There also appeared to be some revival in traditional leadership. Local political actors have included traditional leaders and Ward Councillors, and although dominant locally, both are aware of the obstacles they face in influencing district, provincial and national political priorities. From their perspective, the project provided leverage for their local priorities and issues, and an evidence base for gaps in implementation. As political divisions at municipal level have become more acute, traditional leaders have been seen as more stable and dependable by the people. The participation 
of headmen in the community meetings associated with the project tended to raise their credibility.

The empowerment of the trainers was particularly notable, as these dynamic social actors gained in terms of their standing within the community and with traditional leaders and councillors, personal knowledge and skills, and certification of their knowledge - a matter of considerable civic pride. Similarly the facilitators, who (despite not having the full range of training of the trainers) were shown to have learned and applied their knowledge and skills, now have the acknowledged character of development practitioners.

One conclusion is that the project created new roles and responsibilities that, were it not for political divisions within municipalities, may well have led to a considerably expanded role over time. This is particularly important in the context of the pronounced urban bias in South African society, including in terms of resources to urban civil society to the neglect of rural groups. A second conclusion is that the project strengthened the credibility of local political representatives in speaking to the needs of the wider community. The Ward Forums brought together social and political actors on a new political platform from which community priorities could be asserted and communicated. The project led to a cementing of relations among local political leaders: from the Council the Speaker helped develop a strategy for the cascade on a Ward level and set this work as an

\section{Notes}

* Research interventions: Individual interviews with trainers, facilitators, municipal officials, civil society, and politicians. Focus Group Discussion in Ward 20, Mangqofoza Community Hall, 21 October 2008; Focus Group Trainers and Facilitators, Mbizana, 21 October 2008. essential aspect of councillors' activities. The training of local citizens was a critical element in this endorsement.

The project also highlighted the coordination challenges between the local and district levels of the municipality. Whatever the internal mechanisms for communication and resolution of issues arising at the local level, these were inoperative. This involved the project in a major risk that the work being undertaken at a community level would not lead to results. These problems were critical to a response to local community priorities but were not the subject which could be resolved by the project. Communication of the results of the community appraisal occurred but did not lead to redress.

There has been impact on the lives of people involved directly and indirectly in the project. People have gained training and knowledge of all the elements of water services has been widely dispersed through the cascade. Communities are proud of their participation and the impact of the work continues after the completion of the project as trainers continue to provide training to individuals and groups in the communities.

Despite all this, there has not been a direct material impact from the project. The project did lead to an intense awareness of the rights that all South African citizens have to water and sanitation. Following the conclusion of the project, this translated into equally intense disappointment that the well-constructed representations did not lead to immediate change.

1 Funding was provided by the Water Research Commission, WRC K5/1522/3.

2 Preliminary analysis conducted by Ben Roberts and David Hemson of SASAS 2007.

3 Conducted by reading the Water Service Delivery Plans and the Integrated Development Plans of eThekwini municipality. 


\section{References}

Eastern Cape, PGDP (2004) Provincial Growth and Development Plan, PGDP 2004-2014. Spatial

Planning, www.ecprov.gov.za/index.php?module $=\operatorname{pgdp}$

Hemson, D. and Owusu-Ampomah, K. (2005) 'A

Better Life for All? Service Delivery and Poverty Alleviation', in John Daniel, Roger Southall, and Jessica Lutchman (eds), State of the Nation, South Africa 2004-2005, HSRC: 511-40

Hemson, David; Shirley, Robyn and Munthree, Crystal (2007) The View from Below: Citizen Voice and Regulation in Water Services, Report on the work of the HSRC research team, Pretoria: Water Research Commission

Hoogerwerf, Tanya (2007) Water and Sanitation in Mbizana Local Municipality Current Service
Delivery Status and Recommendations, 22 March, United Nations Development Programme (UNDP)

KwaZulu-Natal, Department of Local Government and Traditional Affairs (DLGTA) (undated) 'Developmental local governance through constructive participatory processes between municipalities and communities', Manual on Improving Participation, DLGTA

PCAS, The Presidency (2008) Fifteen Year Review, Pretoria: Policy Co-ordination and Advisory Services

STATSSA (2007) Community Survey, 2007.

Municipal Data on Household Services Report 03-01-22, Statistics South Africa 